\title{
Interactive Teaching Units in Physics
}

\author{
Summary \\ The concept of the interactive teaching unit first emerged in the late 1970s (Reid, \\ 1978; Johnstone and Reid, 1979) arising from a major research project which was \\ seeking to explore the development of attitudes relating to the themes covered in the \\ study of chemistry. From this project, a sound educational underpinning was \\ developed (Johnstone and Reid, 1981).
}

Much later, the use of interactive units has been extended to skills development, social issues awareness and the applications of science subjects in real-life situations (Reid, 1999; Clarkeburn et al., 2000; Lennon, et al., 2002). Sets of units were developed in chemistry and biology and, more recently, a range of four teaching units in physics was developed under LTSN funding.

Subject area: Physics

An interactive teaching unit is a free standing teaching resource where students have to solve a problem. The problem is based on a real-life situation with varying degrees of simplification and simulation. The units are short (typically from 1 hour to 3 hours) and designed to fit into traditional tutorial and laboratory timings. Students usually work in small groups.

By experiencing different views of the same issue, students are encouraged to recognise the many facets of real-life decision taking and to accept that decisions often have to be made on the basis of incomplete information. Students will also have opportunities to assess data presented in several forms, to weigh arguments, to contribute to a group discussion, to present arguments based on gathered evidence and to listen to the arguments proposed by others. They should begin to see the place of such skills in the context of their education in physics and in the world of work.

The project developed and tested teaching units for use at level 1 of undergraduate courses in physics. They do not seek to teach physics but to apply physics into reallife situations. They involve paper-based group work and contain a full tutor's guide. They are relatively short, being suitable for tutorial use. While focussing on physics applications, their use involves group discussion, debate and argument as well as opportunities for developing presentational skills. Supplementary activities are suggested. The features of the units are:

(1) They are based on real-life problems

(2) Students work in small groups, with opportunities for students to practise team work and communication skills.

(3) Students have to apply their subject knowledge and experience in developing possible solutions, reflecting experiences that might occur in the world of work.

(4) They are paper-based and are fairly short, making them economical in materials and in time. 
(5) They can be used to replace traditional teaching in that the same subject matter is covered or they can be used to reinforce and apply subject teaching

(6) They are self contained, with complete tutors guides. The guides offer clear instructions about how the units can be used, with background information, 'answers' where appropriate, and suggestions for extension activities.

The four units are:

Renewing Energy After a brief introduction, students work in collaborative groups of three to assess the key features of a range of primary sources of energy in order to make a recommendation about national policy to meet the requirements of the Renewables Obligation, a Parliamentary Order which came into effect in 2001, compelling all electricity suppliers to source at last $10 \%$ of their power from renewable sources by 2010 .

Mobile Phones

After a brief introduction, students work in role play groups representing various view points to develop a policy for the installation of phone masts on an imaginary island where competing interests are strong.

Fibre Optics

Students are required to consider the essential physics of the use of fibre optics and then, working in small groups, they assess data provided on various materials and make selections of materials for various applications: communications and endoscopes.

Colour After an introduction which deals with the nature of colour in terms of spectra, incident light and colour perception, students work in pairs to look at one primary colour, seeking to select potential colours for use in road signs. They come together to exchange their findings and come up with a set of three colours which are suitable for use. Colour matching functions are considered as a supplement.

The main aim of the units is not to teach about themes in physics but students are required to use their knowledge of the relevant physics to interpret information in order to take decisions and make choices. They will begin to see how the principles of physics are applied in taking decisions which will affect all our lives. At the end of units, students may be expected to achieve aims like:

(a) Being more aware of the physics related to the topic, and the issues surrounding interpretation.

(b) Gaining experience in understanding and interpreting data.

(c) Appreciating that there may be several factors which have to be considered in taking decisions relating to physics.

(d) Understanding that practical decisions have to take account of physical realities and social acceptability.

(e) Accepting that discussion and compromise are part of commercial decision taking. 
In addition, students will gain valuable experience in skills like group working, discussing and negotiating, make presentations verbally or in writing.

The units are designed to be integrated into teaching programmes and not seen as an add on. The tutor's role is more of a manager and not the provider of information, an important change but not always easy at the outset. Debriefing afterwards is essential and this offers a useful time of reflection about the physics, the issues and the way solutions can be found. The suggested extension activities allow students to apply the ideas under consideration.

With the earliest set of interactive units, there was extensive evaluation and subsequent units have been evaluated in varying ways for a wide range of purposes. Overall, a consistent observation is that students DO participate with enthusiasm. Although the units do not primarily seek to teach a subject, the evidence is that they are quite effective in teaching subject matter (although not necessarily better than any other way). Growth of skills is observed (like team working and communication skills) while attitudes of social awareness develop markedly. There is clear evidence that there is what has been called a 'softening' of a physical science as the participants begin to appreciate the way science and lifestyle interact. The open-ended nature of units may be important. Students are found to be positively disposed to the units, to the teaching style and to the subject matter. This particular set of units was trialled with a few groups of students and there was open discussion afterwards with them. Minor adjustments were made in the light of the student reactions.

\section{Further comments}

The physics units were developed and written by Graham Watt and appreciation is also expressed to Andrew Davies and Rex Whitehead for invaluable support in the project.

The physics units can be downloaded at:

http://www.physsci.ltsn.ac.uk/pubsfinx.asp?ID=168

Details about the units in chemistry and biology can be obtained from the author

(N.Reid@mis.gla.ac.uk).

\section{Author(s)}

Norman Reid, University of Glasgow

\section{Contact details}

Dr Norman Reid, Centre for Science Education, St Andrews Building, University of Glasgow, Glasgow, G3 6NH

N.Reid@mis.gla.ac.uk

\section{References}

1. Reid, N., Simulations and Games in the Teaching of Chemistry, Perspectives in Academic Gaming and Simulations, 1, 92-97, (1978) Kogan Page. 
New Directions in the Teaching of Physical Sciences

2. Johnstone, A.H. and Reid, N., Bringing Chemical Industry into the Classroom, Chemistry and Industry, 4, 122-123 (1979).

3. Johnstone, A.H. and Reid, N., Towards a Model for Attitude Change, International. Journal Science Education, 3(2), 205-212 (1981).

4. Reid, N., Bringing Work Experience to Undergraduates, Education. in Chemistry, 36(1), 23-24, (1999)

5. Clarkeburn, H, Beaumont, E., Downie, R., Reid, N, Teaching Biology Students Transferable Skills, Journal of Biological Education, 34(3), 133-137 (2000).

6. Lennon, D., Freer, A.A., Winfield, J.M., Landon, P and Reid, N., An Undergraduate Teaching Initiative to Demonstrate the Complexity and Range of issues Typically encountered in Modern Industrial Chemistry, Green Chemistry, 4, 181-187 (2002). 